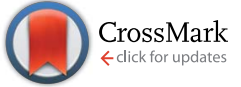

Cite this: RSC Adv., 2017, 7, 4639

Received 1st December 2016 Accepted 23rd December 2016

DOI: $10.1039 / c 6 r a 27626 a$

www.rsc.org/advances

\section{Dicarabrol A, dicarabrone $C$ and dipulchellin $A$, unique sesquiterpene lactone dimers from Carpesium abrotanoides $\dagger$}

\author{
Jie-Wei Wu, ${ }^{\text {ab }}$ Chunping Tang, ${ }^{a}$ Chang-Qiang Ke, ${ }^{a}$ Sheng Yao, ${ }^{a}$ Hong-Chun Liu, ${ }^{a}$ \\ Li-Gen Lin*c and Yang Ye*ad
}

\begin{abstract}
Three rare sesquiterpene lactone dimers, dicarabrol A (1), dicarabrone $C$ (2) and dipulchellin A (3), were isolated from the whole plants of Carpesium abrotanoides. Their structures were elucidated by comprehensive analyses of NMR and MS spectroscopic data. The structure of dipulchellin A was further confirmed by single-crystal X-ray crystallography. Compounds 1 and 2 possessed an unusual carbon skeleton with two carabranolide moieties linking through a spirotetrahydrofuran ring, which was presumably formed by a [ $4+2]$ cycloaddition. Compound 3 was a $[3+2]$ cycloaddition product of a guaianolide moiety and a carabranolide moiety linking through a cyclopentane ring. Their plausible biosynthetic pathways were also proposed. Compounds 1-3 showed moderate cytotoxicity against HL60 cells with $I C_{50}$ values of $8.7 \pm 0.3,8.2 \pm 0.3$ and $8.9 \pm 0.4 \mu \mathrm{M}$, respectively.
\end{abstract}

\section{Introduction}

In the past decade, a series of sesquiterpenoid dimers with unusual carbon skeletons have been reported. ${ }^{1}$ The complex linkage patterns, along with their multiple chiral centres, make the sesquiterpenoid dimers exhibit more "biologically friendly" and "drug-like" molecular features than their monomers. ${ }^{\mathbf{1 , 2}}$ Sesquiterpenoid dimers have been considered as promising drug candidates, and have gathered considerable research interest recently.

The genus Carpesium (Asteraceae) consists approximately of 21 species, which are mainly distributed in Asia, especially in Southwest China. ${ }^{3}$ The fruits of Carpesium abrotanoides L., known as "Nan-He-Shi" in Chinese, are used as insecticides in Northern China. ${ }^{4}$ Phytochemical investigations on this species have led to the isolation of a number of sesquiterpenoid monomers and dimers..$^{5-8}$ C. abrotanoides was also discovered

\footnotetext{
${ }^{a}$ State Key Laboratory of Drug Research, Shanghai Institute of Materia Medica, Chinese Academy of Sciences, Shanghai 201203, P. R. China. E-mail: yye@mail.shcnc.ac.cn ${ }^{b}$ University of Chinese Academy of Sciences, Beijing 100049, P. R. China

${ }^{c}$ State Key Laboratory of Quality Research in Chinese Medicine, Institute of Chinese Medical Sciences, University of Macau, Macao 999078, P. R. China.E-mail: ligenl@ umac.mo

${ }^{d}$ School of Life Science and Technology, Shanghai Tech University, Shanghai 201203, P. R. China

$\dagger$ Electronic supplementary information (ESI) available: Detailed description of the experimental procedures, a listing of NMR, IR and HRESIMS spectra of compounds 1-3, as well as crystallographic data of 3 in CIF (CCDC 1479445). For ESI and crystallographic data in CIF or other electronic format see DOI: 10.1039/c6ra27626a
}

with diverse biological activities such as anti-inflammatory, ${ }^{9}$ antitumor, ${ }^{7}$ antiplasmodial, ${ }^{10,11}$ and bactericidal effects. ${ }^{12}$

In our previous studies, dicarabrones $\mathrm{A}$ and $\mathrm{B}$, dimeric sesquiterpene lactones connecting by a cyclopentane ring, were isolated from the whole plants of $C$. abrotanoides. ${ }^{7}$ As a continuing search for cytotoxic sesquiterpenoids, the whole plants of C. abrotanoides was thoroughly isolated. Three new sesquiterpene lactone dimers, dicarabrol A (1), dicarabrone C (2) and dipulchellin A (3), were identified. Compounds 1 and 2 possessed an unusual carbon skeleton with two carabranolide moieties linking through a spiro-tetrahydrofuran ring, which was presumably formed by a $[4+2]$ cycloaddition. Compound 3 was a $[3+2]$ cycloaddition product of a guaianolide moiety and a carabranolide moiety linking through a cyclopentane ring. Herein, the isolation, structure characterization, proposed biosynthetic pathways, and cytotoxicity of these three compounds are presented.

\section{Results and discussion}

The air-dried whole plant of $C$. abrotanoides was extracted with $95 \%$ ethanol at room temperature (3 times, each 3 days) to afford a crude extract. After partitioned between $\mathrm{CH}_{2} \mathrm{Cl}_{2}$ and $\mathrm{H}_{2} \mathrm{O}$, a $\mathrm{CH}_{2} \mathrm{Cl}_{2}$ fraction was obtained. The $\mathrm{CH}_{2} \mathrm{Cl}_{2}$ fraction was subjected to column chromatography (CC) over MCI gel eluted with $\mathrm{EtOH} / \mathrm{H}_{2} \mathrm{O}(50 \%$ to $95 \%)$ to yield fractions A-C. Fraction B was then subjected to $\mathrm{CC}$ over silica gel eluted with $\mathrm{CH}_{2} \mathrm{Cl}_{2} /$ $\mathrm{MeOH}(50: 1$ to $10: 1)$ to give seven subfractions (B1-B7). Subsequently, subfractions B3-B5 were further purified by CC over Sephadex LH-20 (MeOH) and then preparative HPLC $\left(\mathrm{CH}_{3} \mathrm{CN} / \mathrm{H}_{2} \mathrm{O}\right.$ from $30 \%$ to $\left.60 \%\right)$, yielding 1 (32 mg), 2 (38 mg) and 3 (88 mg) (Fig. 1). 


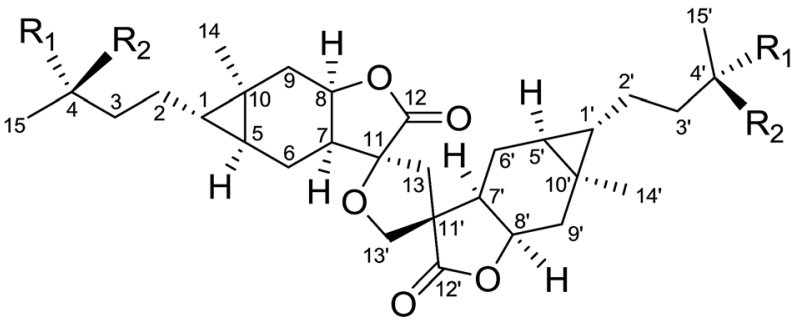

$1 \mathrm{R}_{1}=\mathrm{OH} ; \mathrm{R}_{2}=\mathrm{H} \quad 2 \mathrm{R}_{1}=\mathrm{O} ; \mathrm{R}_{2}=\mathrm{O}$

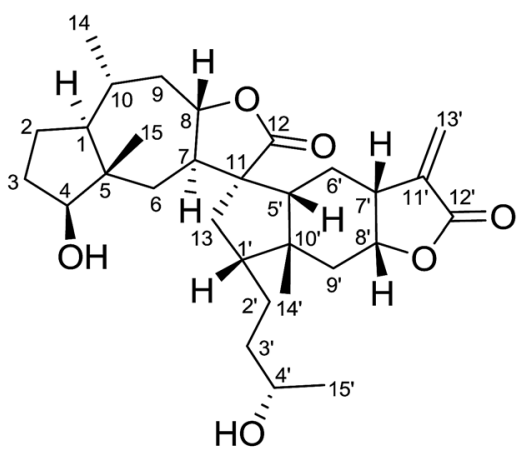

3

Fig. 1 The structures of dicarabrol A (1), dicarabrone $C$ (2) and dipulchellin A (3).

Dicarabrol A (1) was obtained as a yellow amorphous powder, and its molecular formula was assigned to be $\mathrm{C}_{30} \mathrm{H}_{44} \mathrm{O}_{7}$ from the positive ion peak at $\mathrm{m} / \mathrm{z} 539.2974\left([\mathrm{M}+\mathrm{Na}]^{+}\right.$, calcd 539.2985) in the HRESIMS, requiring 9 degrees of unsaturation. The ${ }^{13} \mathrm{C}$ NMR and DEPT spectra of $\mathbf{1}$ displayed 30 carbon resonances including 4 methyls, 10 methylenes, 10 methines, and 6 quaternary carbons. The IR absorption at $1772 \mathrm{~cm}^{-1}$, along with two carbonyl carbons at $\delta_{\mathrm{C}} 176.8$ and 175.4 , clearly suggested the existence of two lactone rings in the molecule of $\mathbf{1}$. The IR spectrum also suggested the existence of hydroxyl groups (3432 $\mathrm{cm}^{-1}$ ). The ${ }^{1} \mathrm{H}$ NMR and HSQC spectra of 1 revealed the presence of four oxygenated methines at $\delta_{\mathrm{H}} 4.96(\mathrm{~m}), 4.82(\mathrm{~m})$ and $3.80(\mathrm{~m}, 2 \mathrm{H})$, one oxygenated methylene at $\delta_{\mathrm{H}} 3.97(\mathrm{~m}, 2 \mathrm{H})$, two singlet methyls at $\delta_{\mathrm{H}} 1.09$ and 1.07 , and two doublet methyls at $\delta_{\mathrm{H}} 1.20(J=6.2 \mathrm{~Hz}$ ) and $1.19(J=6.2 \mathrm{~Hz})$ (Table 1). Additionally, two typical methine protons at $\delta_{\mathrm{H}} 0.46(\mathrm{~m})$ and $0.38(\mathrm{~m})$ (Table 1) were indicative of the presence of two cyclopropane fragments. These characteristic signals, together with the MS data, suggested that $\mathbf{1}$ might be a sesquiterpene lactone dimer.

On the basis of analysis of the ${ }^{1} \mathrm{H}-{ }^{1} \mathrm{H}$ COSY and $\mathrm{HMBC}$ spectra of $\mathbf{1}$, two carabranolide moieties were constructed (Fig. 2), whose ${ }^{1} \mathrm{H}$ and ${ }^{13} \mathrm{C}$ NMR data showed great similarity to those of carabrol. ${ }^{13}$ The major difference was an oxygen-bearing quaternary carbon $\left(\delta_{\mathrm{C}} 85.3\right)$ and a methylene $\left(\delta_{\mathrm{H}} 2.71, \mathrm{~d}, J=13.2\right.$ $\left.\mathrm{Hz} ; 2.15, \mathrm{~m} / \delta_{\mathrm{C}} 40.7\right)$ in the moiety $1 \mathrm{a}$, and a quaternary carbon $\left(\delta_{\mathrm{C}} 52.8\right)$ and an oxygen-bearing methylene $\left(\delta_{\mathrm{H}} 3.97, \mathrm{~m}, 2 \mathrm{H} / \delta_{\mathrm{C}}\right.$ $71.4)$ in the moiety $\mathbf{1 b}$, were observed instead of the exocyclic double bond between $\mathrm{C}-11$ and $\mathrm{C}-13$ in carabrol. The linkage between the two moieties was established by the HMBC correlations (Fig. 2). The HMBC cross-peaks between $\mathrm{H}-13\left(\delta_{\mathrm{H}} 2.71\right.$;
2.15) and $\mathrm{C}-12\left(\delta_{\mathrm{C}} 175.4\right), \mathrm{C}-7^{\prime}\left(\delta_{\mathrm{C}} 44.0\right)$, and $\mathrm{C}-11^{\prime}\left(\delta_{\mathrm{C}} 52.8\right)$ indicated a $\mathrm{C}-\mathrm{C}$ bond between $\mathrm{C}-13$ and $\mathrm{C}-11^{\prime}$. And the HMBC correlations from $\mathrm{H}-13^{\prime}\left(\delta_{\mathrm{H}} 3.97\right)$ to $\mathrm{C}-11\left(\delta_{\mathrm{C}} 85.3\right)$ and $\mathrm{C}-13\left(\delta_{\mathrm{C}}\right.$ 40.7) suggested a $\mathrm{C}-\mathrm{O}-\mathrm{C}$ linage between $\mathrm{C}-11$ and $\mathrm{C}-13^{\prime}$. Thus, a unique spiro-tetrahydrofuran ring was constructed connecting the two carabranolide moieties.

The relative configuration of $\mathbf{1}$ was inferred from the ROESY experiment (Fig. 3). The cross-peaks of $\mathrm{H}-5 / \mathrm{H}_{3}-14, \mathrm{H}-7 / \mathrm{H}-8, \mathrm{H}-5^{\prime} /$ $\mathrm{H}_{3}-14^{\prime}$, and $\mathrm{H}-7^{\prime} / \mathrm{H}-8^{\prime}$ suggested cis-diaxial like structure of two carabranolide units. Additionally, the ROESY cross-peaks of $\mathrm{H}-$ $5 / \mathrm{H}-6 \alpha, \mathrm{H}-6 \alpha / \mathrm{H}_{\mathrm{b}}-13, \mathrm{H}_{2}-13^{\prime} / \mathrm{H}-6^{\prime} \beta, \mathrm{H}_{3}-14^{\prime} / \mathrm{H}-6^{\prime} \alpha$, suggested that $\mathrm{H}-5, \mathrm{H}-6 \alpha$, and $\mathrm{H}_{\mathrm{b}}-13$ are on the same face, while $\mathrm{H}-6^{\prime} \beta$, and $\mathrm{H}_{2}-13^{\prime}$ are on the other face. Considering the biogenetic relationship between $\mathbf{1}$ and carabrol, the absolute configuration of $\mathbf{1}$ was determined as $1 S, 4 S, 5 S, 7 S, 8 R, 10 R, 11 S, 1^{\prime} S, 4^{\prime} S, 5^{\prime} S, 7^{\prime} R$, $8^{\prime} R, 10^{\prime} R, 11^{\prime} R$. Taken together the structure of 1 was determined.

Dicarabrone C (2) was obtained as a yellow amorphous powder. The HRESIMS indicated a molecule formula of $\mathrm{C}_{30} \mathrm{H}_{40} \mathrm{O}_{7}\left(\mathrm{~m} / \mathrm{z}\right.$ 535.2680, $[\mathrm{M}+\mathrm{Na}]^{+}$, calcd for 535.2672). Comparison of the ${ }^{1} \mathrm{H}$ and ${ }^{13} \mathrm{C}$ NMR data of 2 with those of $\mathbf{1}$ revealed a high degree of similarity. The only difference was two hydroxy-methines in $\mathbf{1}$ were replaced by two carbonyl groups $\left(\delta_{\mathrm{C}}\right.$ 208.9, C-4/208.9, C-4 $4^{\prime}$ in 2. Further analysis of the ${ }^{1} \mathrm{H}-{ }^{1} \mathrm{H}$ COSY and HMBC data revealed that 2 was a dimer of two carabrone moieties with the same skeleton as $\mathbf{1}$. The NOESY correlations of $\mathrm{H}_{2}-13^{\prime} / \mathrm{H}-6^{\prime} \beta$ and $\mathrm{H}-6 \alpha / \mathrm{Hb}-13$ indicated the spiro-tetrahydrofuran ring possessed the same configuration as that of $\mathbf{1}$. Similarly, the absolute configuration of 2 was determined as $1 S, 5 S, 7 S, 8 R, 10 R$, $11 S, 1^{\prime} S, 5^{\prime} S, 7^{\prime} R, 8^{\prime} R, 10^{\prime} R, 11^{\prime} R$, based on its biogenetic relationship with carabrone. Thus, the structure of 2 was determined.

Dipulchellin A (3) was obtained as white lamellar crystals. Its molecular formula $\mathrm{C}_{30} \mathrm{H}_{44} \mathrm{O}_{6}$ was determined by the positive ion peak at $m / z 523.3020\left([\mathrm{M}+\mathrm{Na}]^{+}\right.$, calcd 523.3030) in the HRESIMS, indicating 9 degrees of unsaturation. The IR spectrum indicated the presences of hydroxyl groups $\left(3444 \mathrm{~cm}^{-1}\right)$ and ester carbonyl groups $\left(1755 \mathrm{~cm}^{-1}\right)$. The ${ }^{13} \mathrm{C}$ and DEPT NMR spectra of 3 showed 30 carbon resonances due to 4 methyls, 10 methylenes, 10 methines, and 6 quaternary carbons (Table 1). The ${ }^{1} \mathrm{H}$ NMR spectrum of 3 showed the signals of four oxygenated methines at $\delta_{\mathrm{H}} 3.72(\mathrm{~m}), 3.77(\mathrm{~m}), 4.24(\mathrm{dt}, J=4.3,10.9 \mathrm{~Hz})$, and $4.69(\mathrm{dt}, J=7.2,10.3 \mathrm{~Hz})$, two singlet methyls at $\delta_{\mathrm{H}} 0.88$ and 1.15 , and two doublet methyls at $\delta_{\mathrm{H}} 0.91(J=6.5 \mathrm{~Hz})$ and $1.19(J$ $=6.1 \mathrm{~Hz}$ ) (Table 1). From these resonances, one $\alpha$-methylene- $\gamma$ lactone moiety $\left(\delta_{\mathrm{H}} 5.60, \mathrm{~d}, J=1.9 \mathrm{~Hz} ; 6.23, \mathrm{~d}, J=1.9 \mathrm{~Hz} ; \delta_{\mathrm{C}}\right.$ 170.1, 139.0 and 123.3) and a lactone carbonyl carbon $\left(\delta_{\mathrm{C}} 178.5\right)$ could be identified. The NMR and MS data suggested that 3 might be a sesquiterpene lactone dimer. Extensive analysis of the 1D and 2D NMR spectra of 3 led to the identification of two moieties (Fig. 4). The moiety 3a was assembled based on the ${ }^{1} \mathrm{H}^{-}{ }^{1} \mathrm{H}$ COSY correlations $\left(\mathrm{H}_{2}-2 / \mathrm{H}_{2}-3 / \mathrm{H}-4\right.$ and $\mathrm{H}_{2}-6 / \mathrm{H}-7 / \mathrm{H}-8 / \mathrm{H}_{2}-$ 9/H-10/ $\left.\mathrm{H}_{3}-14\right)$ and the key HMBC correlations $\left(\mathrm{H}_{3}-14 / \mathrm{C}-1, \mathrm{C}-9\right.$, $\mathrm{H}_{3}-15 / \mathrm{C}-4$, C-6, and $\left.\mathrm{H}-8 / \mathrm{C}-11, \mathrm{C}-12\right)$. The ${ }^{1} \mathrm{H}$ and ${ }^{13} \mathrm{C}$ NMR data of the moiety 3a were very similar to those of 2-desoxy-4-epipulchellin ${ }^{6}$ except a methylene $\left(\delta_{\mathrm{H}} 1.74, \mathrm{~m} ; 2.11, \mathrm{~m} / \delta_{\mathrm{C}} 40.8\right)$ and a quaternary carbon $\left(\delta_{\mathrm{C}} 57.4\right)$ in the moiety $3 \mathrm{a}$ instead of the 
Table $1{ }^{1} \mathrm{H}$ and ${ }^{13} \mathrm{C}$ NMR data for compounds $1-3$ in $\mathrm{CDCl}_{3}$

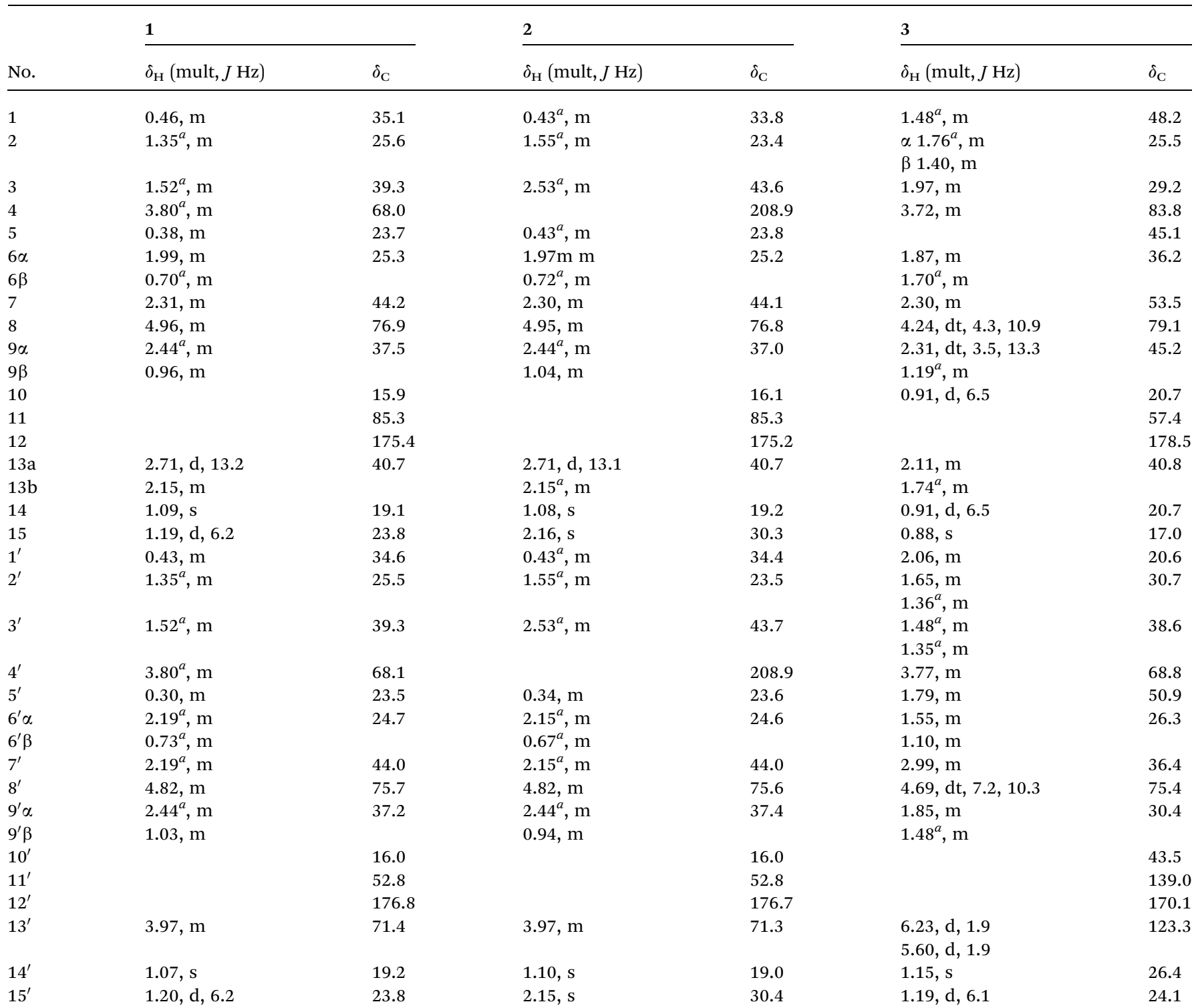

${ }^{a}$ Signals overlapped.

exocyclic double bond between C-11 and C-13 in 2-desoxy-4-epipulchellin. The remaining signals indicated a 1,5-seco carabrol unit for moiety $\mathbf{3 b}$.

\section{Moiety 1a}

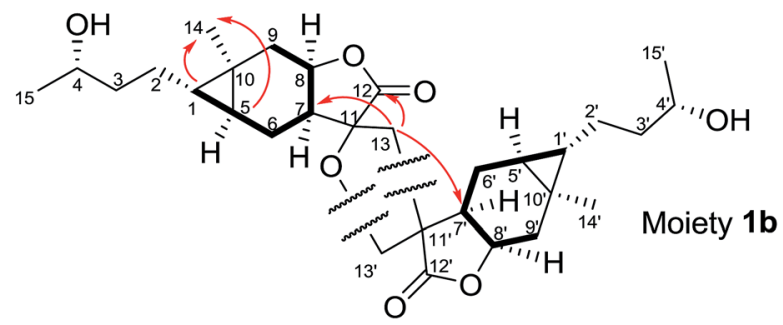

Fig. 2 Key ${ }^{1} \mathrm{H}^{1}{ }^{1} \mathrm{H} \operatorname{COSY}(-)$ and $\mathrm{HMBC}$ correlations $(\mathrm{H} \rightarrow \mathrm{C})$ of 1.
The connection between the moieties $\mathbf{3 a}$ and $\mathbf{3} \mathbf{b}$ was first indicated by the ${ }^{1} \mathrm{H}-{ }^{1} \mathrm{H}$ COSY correlation between $\mathrm{H}_{2}-13$ and $\mathrm{H}$ $1^{\prime}$. Further evidence from the HMBC correlations between $\mathrm{H}_{2}-13$ and C-7 $\left(\delta_{\mathrm{C}} 53.5\right), \mathrm{C}-12\left(\delta_{\mathrm{C}} 178.5\right), \mathrm{C}-5^{\prime}\left(\delta_{\mathrm{C}} 50.9\right)$, and C-10 ${ }^{\prime}\left(\delta_{\mathrm{C}}\right.$ 43.5) confirmed the $\mathrm{C}-\mathrm{C}$ bond between $\mathrm{C}-13$ and $\mathrm{C}-\mathbf{1}^{\prime}$. Additionally, the HMBC correlations from $\mathrm{H}^{\prime} 5^{\prime}\left(\delta_{\mathrm{H}} 1.79, \mathrm{~m}\right)$ to $\mathrm{C}-7$,

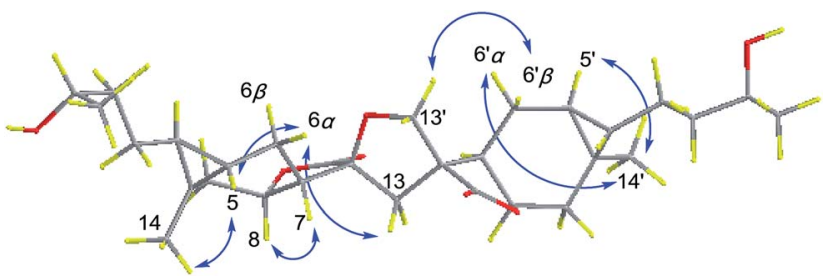

Fig. 3 Key ROESY correlations of 1. 


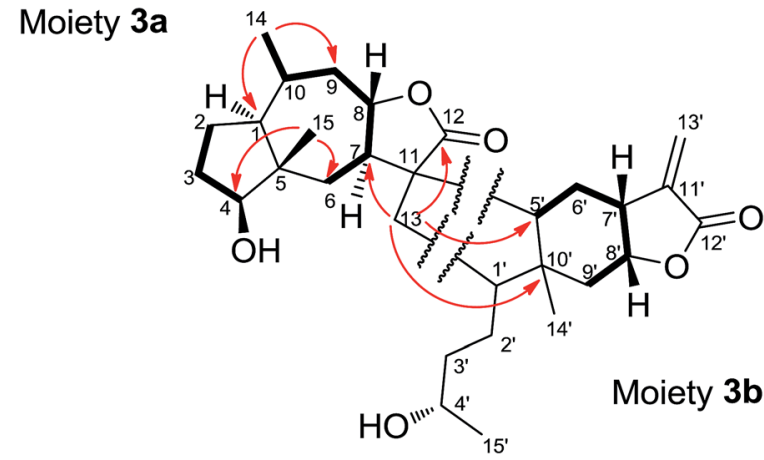

Fig. 4 Key ${ }^{1} \mathrm{H}-{ }^{1} \mathrm{H}$ COSY $(-)$ and $\mathrm{HMBC}$ correlations $(\mathrm{H} \rightarrow \mathrm{C})$ of 3 .

and $\mathrm{H}-7\left(\delta_{\mathrm{H}} 2.30, \mathrm{~m}\right)$ to $\mathrm{C}-5^{\prime}$ indicated another $\mathrm{C}-\mathrm{C}$ bond between $\mathrm{C}-11$ and $\mathrm{C}-5^{\prime}$. Thus, a cyclopentane ring was constructed to connect the 2-desoxy-4-epi-pulchellin and carabrol moieties. Due to the overlapping of the key ROESY correlations, the configuration of the cyclopentane moiety could not be fully determined. The X-ray crystallographic analysis established unambiguously the absolute configuration of 3 as $1 S, 4 S, 5 S, 7 R$, $8 S, 10 R, 11 S, 1^{\prime} R, 4^{\prime} S, 5^{\prime} R, 7^{\prime} R, 8^{\prime} R$, and $10^{\prime} R$ (Fig. 5).

Dicarabrol A (1) and dicarabrone C (2) possess two carabranolide units linking through a spiro-tetrahydrofuran ring, which are rarely discovered in nature and, thus, of particular significance from the perspective of biosynthesis. To the best of our knowledge, only one example of sesquiterpenoid dimer, featured with the spiro-tetrahydrofuran ring, was reported in the previous study. ${ }^{14}$ Accordingly, a plausible biosynthetic pathway of dicarabrol A (1) and dicarabrone C (2) was proposed in Scheme 1A. The key step of this biosynthetic pathway might be the $[4+2]$ Diels-Alder cycloaddition. Carabrol and carabrone were previously reported from this species, which could be considered as the parent compounds. First, the double bond $\left(\mathrm{C}-11^{\prime}=\mathrm{CH}_{2}-13^{\prime}\right)$ of one carabrol/carabrone might undergo [ $4+$ 2] Diels-Alder cycloaddition with the $\alpha, \beta$-unsaturated carbonyl $\left(\mathrm{CH}_{2}-13=\mathrm{C}-11-\mathrm{C}-12=\mathrm{O}\right)$ of another carabrol/carabrone, to form the key intermediate molecule I (KIM I) with a dihydropyran ring. Then the double bond of the dihydropyran could

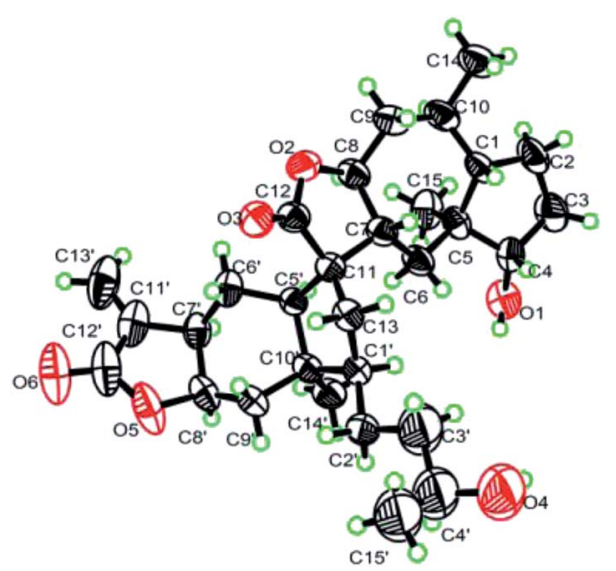

Fig. 5 X-ray crystallographic structure of 3.
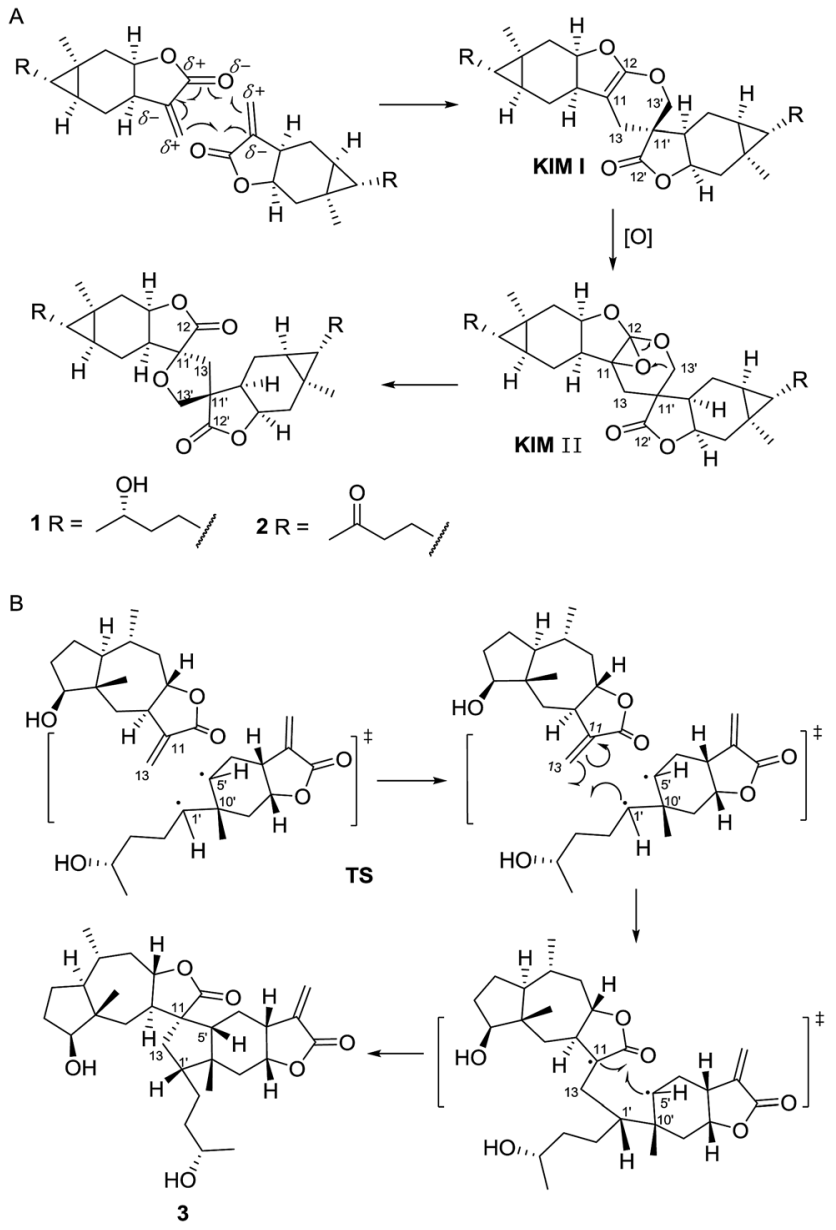

Scheme 1 Proposed biosynthetic pathway for dicarabrol A (1), dicarabrone C (2) and dipulchellin A (3).

be enzymatically oxygenated to yield an oxirane fragment in KIM II. Last, two C-O bonds could be displaced each other to generate the tetrahydrofuran ring in dicarabrol $\mathrm{A}$ /dicarabrone $\mathrm{C}$.

The skeleton of dipulchellin A (3) features a cyclopentane ring linking a guaianolide unit and a carabranolide unit. The formation of the cyclopentane ring is quite unique. So far a number of structurally complicated sesquiterpenoid dimers have been isolated, and most of them were proposed to be biosynthesized through a $[4+2]$ or $[2+2]$ cycloaddition of two monomers. ${ }^{1,2}$ In the current case, the carabrone monomer possesses a cyclopropane ring and the 2-desoxy-4-epi-pulchellin monomer possesses a double bond; therefore, the cyclopentane ring might be envisioned to arise from a $[3+2]$ cycloaddition starting from the cyclopropane ring in one monomer and the double bond in the other (Scheme 1B), as proposed in our previous study. ${ }^{7}$ In the proposed biosynthetic pathway, the reaction might take place via radical intermediates. The bond between $\mathrm{C}-\mathrm{1}^{\prime}$ and $\mathrm{C}-5^{\prime}$ could be cleaved to form a radical intermediate, and the radical at $\mathrm{C}^{-5^{\prime}}$ might be then trapped with the double bond. Due to steric hindrance in the structure, C- $1^{\prime}$ could form a new bond with $\mathrm{C}-13$ first, and subsequently C-5' could form the other new bond with $\mathrm{C}-11$. Therefore, a cyclopentane ring might be introduced to fuse two monomers. 
In order to identify anti-tumour substances, compounds 1-3 were evaluated for their cytotoxic effects on A549 and HL-60 cancer cells. Compounds 1-3 exhibited selective cytotoxicity against HL-60 cells with $\mathrm{IC}_{50}$ values of $8.7 \pm 0.3,8.2 \pm 0.3$ and 8.9 $\pm 0.4 \mu \mathrm{M}$, respectively, but no activity on A549 cells ( $\left.\mathrm{IC}_{50}>10 \mu \mathrm{M}\right)$.

\section{Conclusions}

In conclusion, three novel sesquiterpoen lactone dimers were identified from the whole plants of $C$. abrotanoides. Till now, most sesquiterpenoid dimers were proposed to be biosynthesized from two monomeric sesquiterpenoids through a cyclohexene or 3,4dihydro- $2 H$-pyran ring via regular or hetero Diels-Alder cycloadditions. ${ }^{1,2}$ To the best of our knowledge, compounds 1 and 2 are the first examples of carabranolide dimers linking through a spiro-tetrahydrofuran ring; and compound 3 is the first dimer of a guaianolide unit and a carabranolide unit linking through a cyclopentane ring. Moreover, dipulchellin A (3) represents the second example of sesquiterpenoid dimer formed via a $[3+2]$ cycloaddition. Our finding enriches the structure and biosynthesis diversity of sesquiterpenoid dimers. Furthermore, these compounds showed potential cytotoxic effect on HL-60 cells, which might be developed as anti-tumour agents.

\section{Experimental section}

\section{General experimental procedures}

Melting points were obtained on a SGM X-4 apparatus (Shanghai Precision \& Scientific Instrument Co., Ltd., P. R. China). Optical rotations were measured on a Perkin-Elmer 341 polarimeter. IR spectra were recorded on a Nicolet Magna FT-IR 750 spectrophotometer using $\mathrm{KBr}$ disks. NMR spectra were recorded on a Varian Mercury-500 spectrometer. The chemical shift $(\delta)$ values are given in ppm with TMS as internal standard, and coupling constants $(J)$ are in Hz. ESI-MS and ESI-HRMS data were recorded on Waters 2695-3100 LC-MS and Waters Q-TOF Ultima Global mass spectrometers, respectively. Silica gel (Qingdao Marine Chemical Industrials) was used for flash chromatography. MCI gel CHP20P (75-150 $\mu \mathrm{m}$, Mitsubishi Chemical Industries, Japan) and Sephadex LH-20 (Pharmacia Biotech AB, Uppsala, Sweden) were used for column chromatography (CC). TLC was carried out on precoated silica gel $\mathrm{GF}_{254}$ plates (Yantai Chemical Industrials) and the TLC spots were viewed at $254 \mathrm{~nm}$ and visualized with $5 \% \mathrm{H}_{2} \mathrm{SO}_{4}$ in EtOH containing $10 \mathrm{mg} \mathrm{mL}^{-1}$ vanillin. Analytical HPLC was performed on a Waters 2690 instrument with a 996 PAD (photodiode array detector) and coupled with an Alltech ELSD 2000 detector. All solvents used for CC were of at least analytical grade (Shanghai Chemical Reagents Co., Ltd., Shanghai, P. R. China), and solvents used for HPLC were of HPLC grade (J \& K Scientific Ltd., Shanghai, P. R. China).

\section{Plant material}

The whole plants of $C$. abrotanoides L. were collected in Henan Province, P. R. China in 2012, and identified by Professor JinGui Shen from the Shanghai Institute of Materia Medica. A voucher (20120901) was deposited at the Herbarium of the Shanghai Institute of Materia Medica, Chinese Academy of Sciences.

\section{Extraction and isolation}

The air-dried whole plants of C. abrotanoides (50 kg) were extracted three times with 95\% ethanol at room temperature to afford a crude extract $(3.29 \mathrm{~kg})$. The extract was further partitioned between $\mathrm{CH}_{2} \mathrm{Cl}_{2}$ and $\mathrm{H}_{2} \mathrm{O}$, giving a $\mathrm{CH}_{2} \mathrm{Cl}_{2}$-soluble fraction (1.66 kg). The $\mathrm{CH}_{2} \mathrm{Cl}_{2}$-soluble fraction was fractionated over MCI gel (EtOH $/ \mathrm{H}_{2} \mathrm{O}$, from $50 \%$ to $95 \%$ ) to yield fractions A-C. Fraction B (300 g) was then subjected to column chromatography (CC) over silica gel eluted with $\mathrm{CH}_{2} \mathrm{Cl}_{2} / \mathrm{MeOH}(50: 1$ to $10: 1$ ) in a stepwise manner to give seven subfractions (B1-B7). Subsequently, subfractions B3-B5 were selected for purification by CC over Sephadex LH-20 (MeOH) and then preparative HPLC $\left(\mathrm{CH}_{3} \mathrm{CN} / \mathrm{H}_{2} \mathrm{O}\right.$ from $30 \%$ to $60 \%$ ), yielding 1 (32 mg), 2 (38 mg) and 3 ( $88 \mathrm{mg})$.

Dicarabrol A (1). Yellow amorphous powder, $[\alpha]_{\mathrm{D}}^{20}=+68.9(c$ 0.1 in $\mathrm{CH}_{3} \mathrm{OH}$ ); IR (KBr) $\nu_{\max } 3432,2966,2930,2865,1772,1462$, $1202 \mathrm{~cm}^{-1}$; NMR data see Table 1; HRESIMS m/z 539.2974 [M + $\mathrm{Na}]^{+}$(calcd for $\mathrm{C}_{30} \mathrm{H}_{44} \mathrm{O}_{7} \mathrm{Na}, 539.2985$ ).

Dicarabrone C (2). Yellow amorphous powder, $[\alpha]_{\mathrm{D}}^{20}=+86.0$ (c 0.1 in $\mathrm{CH}_{3} \mathrm{OH}$ ); IR (KBr) $\nu_{\max } 3426,2957,2924,2875,1768$, 1701, 1357, 1261, 1202, $1037 \mathrm{~cm}^{-1}$; NMR data see Table 1; HRESIMS $m / z$ 535.2680 $[\mathrm{M}+\mathrm{Na}]^{+}$(calcd for $\mathrm{C}_{30} \mathrm{H}_{40} \mathrm{O}_{7} \mathrm{Na}$, 535.2672).

Dipulchellin A (3). White lamellar crystal, $[\alpha]_{\mathrm{D}}^{20}=+24.7$ ( c 0.1 in $\mathrm{CH}_{3} \mathrm{OH}$ ); IR (KBr) $\nu_{\max } 3444,2957,2932,2871,2359,2340$, 1755, 1455, 1402, 1384, 1269, 1177, 1120, $984 \mathrm{~cm}^{-1}$; NMR data see Table 1; HRESIMS $m / z$ 523.3020 $[\mathrm{M}+\mathrm{Na}]^{+}$(calcd for $\left.\mathrm{C}_{30} \mathrm{H}_{44} \mathrm{O}_{6} \mathrm{Na}, 523.3030\right)$.

\section{X-ray crystallographic analysis}

Dipulchellin A (3) was crystallized from acetone at room temperature. The X-ray crystallographic data was obtained on a Bruker SMART CCD detector employing graphite monochromated $\mathrm{Cu}-\mathrm{K} \alpha$ radiation $(\lambda=1.54178 \AA$ ) (operated in the $\varphi-\omega$ scan mode). The structure was solved by direct method using SHELXS-97 program and refined with full-matrix least-squares calculations on $F^{2}$ using SHELXL-97. Crystallographic data for 3 (key parameters see Table $\mathrm{S} 1 \dagger$ ) have been deposited at the Cambridge Crystallographic Data Centre (Deposition No. CCDC 1479445).

\section{Cytotoxicity bioassays}

The anti-proliferative activities of compounds 1-3 against HL-60 (human leukemia) and A-549 (human lung adenocarcinoma) tumor cell lines were evaluated. Doxorubicin was used as a positive control. Both the HL-60 and A-549 cells were obtained from ATCC.

The anti-proliferative activity of the compounds against HL-60 cells was evaluated using the 3-(4,5-dimethylthiazol-2-yl)2,5-diphenyltetrazolium bromide (MTT) assay. ${ }^{15}$ Exponentially growing HL-60 cells were seeded into 96-well plates. Upon approximately $70-80 \%$, the cells were treated with series concentrations of different compounds for $48 \mathrm{~h}$. DMSO was 
used as the vehicle control. Then, $1 \mathrm{mg} \mathrm{mL}^{-1}$ MTT solution was added to each well and the 96-well plates were further incubated for $4 \mathrm{~h}$ at $37^{\circ} \mathrm{C} .100 \mu \mathrm{L}$ DMSO was added to each well to dissolve the formazan crystals. Absorbance at $570 \mathrm{~nm}$ was measured by a microplate reader (SpectraMax, Molecular Devices, USA). The inhibition rate was calculated as $\left(1-A_{570}\right.$ treated $/ A_{570}$ vehicle control) $\times 100 \%$.

The anti-proliferative activity of the compounds against A549 cells was evaluated using the sulforhodamine B (SRB) assay. ${ }^{16}$ A-549 cells $\left(4 \times 10^{3}\right.$ cell per well $)$ were seeded into 96well plates and grown for $24 \mathrm{~h}$. Cells were then treated with increasing concentrations of compounds and grown for further 72 h. DMSO was used as the vehicle control. At the end of exposure time, $100 \mu \mathrm{L}$ ice-cold $10 \%$ trichloroacetic acid (TCA) was added to each well, left at $4{ }^{\circ} \mathrm{C}$ for $1 \mathrm{~h}$, and washed five times with distilled water. The TCA-fixed cells were stained for $15 \mathrm{~min}$ with $100 \mu \mathrm{L} 4 \mathrm{mg} \mathrm{mL}{ }^{-1} \mathrm{SRB}$ in $1 \%$ HOAc. The plates were washed five times with $1 \%$ HOAc and air-dried overnight. After air-drying, protein-bound dye was dissolved in $150 \mu \mathrm{L} 10 \mathrm{mM}$ Tris base for $5 \mathrm{~min}$ and was measured at $515 \mathrm{~nm}$ using multiwall spectrophotometer (SpectraMax, Molecular Devices, USA). The inhibition rate was calculated as $\left(1-A_{515}\right.$ treated $/ A_{515}$ control) $\times 100 \%$.

\section{Acknowledgements}

We thank the financial support of the National Science \& Technology Major Project "Key New Drug Creation and Manufacturing Program” (No. 2011ZX09307-002-03). Our thanks are also given to the National Natural Science Funds for Distinguished Young Scholar (No. 30925043), grants from the Ministry of Science and Technology (2007DFC31030, 2010DFA30980), the Shanghai Commission of Science and Technology (10DZ1972700, 11DZ1970700, 12JC1410300) and the Science and Technology Development Fund of Macau (FCDT 120/2013/A3).

\section{Notes and references}

1 Z.-J. Zhan, Y.-M. Ying, L.-F. Ma and W.-G. Shan, Nat. Prod. Rep., 2011, 28, 594-629.
2 G.-W. Wang, J.-J. Qin, X.-R. Cheng, Y.-H. Shen, L. Shan, H.-Z. Jin and W.-D. Zhang, Expert Opin. Invest. Drugs, 2014, 23, 317-345.

3 Editor committee, Flora of China, Science Press, Beijing, China, 1979, vol. 75, p. 293.

4 Editor committee, Flora of China, Science Press, Beijing, China, 1979, vol. 75, p. 313.

5 J. S. Lee, B. S. Min, S. M. Lee, M. K. Na, B. M. Kwon, C. O. Lee, Y. H. Kim and K. H. Bae, Planta Med., 2002, 68, 745-747.

6 F. Wang, K. Yang, F.-C. Ren and J.-K. Liu, Fitoterapia, 2009, 80, 21-24.

7 J.-W. Wu, C.-P. Tang, L. Chen, Y. Qiao, M.-Y. Geng and Y. Ye, Org. Lett., 2015, 17, 1656-1659.

8 J.-P. Zhang, G.-W. Wang, X.-H. Tian, Y.-X. Yang, Q.-X. Liu, L.-P. Chen, H.-L. Li and W.-D. Zhang, J. Ethnopharmacol., 2015, 163, 173-191.

9 H. J. Lee, H. J. Lim, D. Y. Lee, H. Jung, M. R. Kim, D. C. Moon, K. I. Kim, M. S. Lee and J. H. Ryu, Biochem. Biophys. Res. Commun., 2010, 391, 1400-1404.

10 E. J. Kim, H. K. Jin, Y. K. Kim, H. Y. Lee, S. Y. Lee, K. R. Lee, O. P. Zee, J. W. Han and H. W. Lee, Biochem. Pharmacol., 2001, 61, 903-910.

11 I. M. Chung and H. I. Moon, J. Enzyme Inhib. Med. Chem., 2009, 24, 131-135.

12 C. Yang, Y.-P. Shi and Z.-J. Jia, Planta Med., 2002, 68, 626630.

13 F. Bohlmann, P. K. Mahanta, J. Jakupovic, R. C. Rastogi and A. A. Natu, Phytochemistry, 1978, 17, 1165-1172.

14 H.-L. Jiang, J. Chen, X.-J. Jin, J.-L. Yang, Y. Li, X.-J. Yao and Q.-X. Wu, Tetrahedron, 2011, 67, 9193-9198.

15 J. Heilmann, M.-R. Wasescha and T.-J. Schmidt, Bioorg. Med. Chem., 2001, 9, 2189-2194.

16 P.-A. Skehan, R. Storeng, A. Monks, J. McMahon, D. Vistica, J.-T. Warren, H. Bokesch, S. Kenney and M.-R. Boyd, J. Natl. Cancer Inst., 1990, 82, 1107-1112. 